\title{
Tin/Tinoxide $\left(\mathrm{Sn} / \mathrm{SnO}_{2}\right)$ Nanocomposites Thin Films as Negative-Electrode Materials for Li-Ion Batteries
}

\author{
M. AlaF*, D. Gultekin and H. Akbulut
}

Sakarya University, Dept. of Metallurgical \& Materials Engineering, 54187, Sakarya, Turkey

\begin{abstract}
In this study, tin/tinoxide $\left(\mathrm{Sn} / \mathrm{SnO}_{2}\right)$ nanocomposites thin films were produced by thermal evaporation and plasma oxidation as anode materials for Li-ion batteries. To produce $\mathrm{Sn} / \mathrm{SnO}_{2}$ thin films, pure metallic tin ( $\mathrm{Sn}$ ) was thermally evaporated on the stainless steel substrates in argon atmosphere. The Sn films were subjected to plasma oxidation process at oxygen/argon gas mixture. Three different plasma oxidation times $(30,45$, and 60 min) were used to investigate oxidation kinetics and physical and microstructural properties. The surface properties were studied by scanning electron microscopy and atomic force microscopy. For structural analysis, X-ray diffraction measurements were carried out. $\mathrm{Sn} / \mathrm{SnO}_{2}$ coated stainless steel substrates were used as the working electrode in coin-type (CR2016) test cells. The energy storage capacity $\mathrm{Sn} / \mathrm{SnO}{ }_{2}$ electrodes were determined depending on the oxidation time and $\mathrm{Sn}: \mathrm{SnO}_{2}$ ratio.
\end{abstract}

DOI: $10.12693 /$ APhysPolA.123.323

PACS: 64.70.fm, 73.61.At, 81.16.Pr, 82.47.Aa, 78.67.Sc

\section{Introduction}

Lithium-ion batteries offer significant advantages in weight and energy density over other rechargeable batteries. They have proven to be ideal for small-scale portable electronic applications such as cellular phones and laptop computers. Emerging applications in implantable medical devices also take advantage of the high cycle life, light weight, and other benefits of Li-ion batteries [1]. Graphite is a standard anode material in Li-ion batteries as lithium can insert and deinsert during discharging and charging, respectively, with a theoretical specific capacity of $372 \mathrm{mAh} \mathrm{g}^{-1}$. However, in order to meet the increasing demand for batteries with higher energy densities, it is essential to develop electrodes made from durable, nontoxic, and inexpensive materials with a high charge/discharge rate and a higher reversible capacity. Among Li-ion batteries anode materials, $\mathrm{SnO}_{2}$-based materials have become one of the promising candidates, as $\mathrm{SnO}_{2}$ has high theoretical capacity, the environmental friendliness of its raw material processing and low cost. In theory, $\mathrm{SnO}_{2}$ exhibit a first discharge capacity of $1494 \mathrm{mAh} \mathrm{g}^{-1}$ and a reversible discharge capacity of $782 \mathrm{mAh} \mathrm{g}^{-1}$ [2].

In this study, tin/tinoxide $\left(\mathrm{Sn} / \mathrm{SnO}_{2}\right)$ films were produced by thermal evaporation and plasma oxidation as anode materials for Li-ion batteries. $\mathrm{Sn} / \mathrm{SnO}_{2}$ coated on stainless steel substrates were used as working electrode in coin-type (CR2016) test cells. The ratio between metallic tin $(\mathrm{Sn})$ and tinoxide $\left(\mathrm{SnO}_{2}\right)$ was controlled with plasma oxidation time and effects of the ratio were investigated on the morphological and electrochemical properties.

\section{Experiment details}

Thermal evaporation of metallic tin on the stainless steel substrates was performed in a multifunctional phys-

*corresponding author ical vapor deposition (PVD) unit equipped with thermal evaporation, dc and $\mathrm{rf}$ units. High purity metallic tin $(99.999 \%)$ was placed in a Mo boat in the deposition chamber, which was evacuated to $10^{-4} \mathrm{~Pa}$ by a turbomolecular pump and then backfilled with argon to a pressure of $1 \mathrm{~Pa}$ to production of Sn films. Then, $\mathrm{Sn} / \mathrm{SnO}_{2}$ films were produced by RF plasma oxidation from the thermally evaporated pure Sn films. Before starting the plasma oxidation process, the chamber was evacuated to $10^{-4} \mathrm{~Pa}$ by a turbomolecular pump. The plasma oxidation of the Sn films were conducted using a high-purity oxygen $(99.999 \%)$ and argon $(99.9999 \%)$ gas mixture in ratio $1: 1$. Three different oxidation times of 30,45 , and 60 min were chosen for plasma oxidation. Total chamber pressure and RF power for each oxidation were kept constant at $1.6 \mathrm{~Pa}$ and $80 \mathrm{~W}$. Figure 1 represents the methods of preparing of the $\mathrm{Sn} / \mathrm{SnO}_{2}$ films.

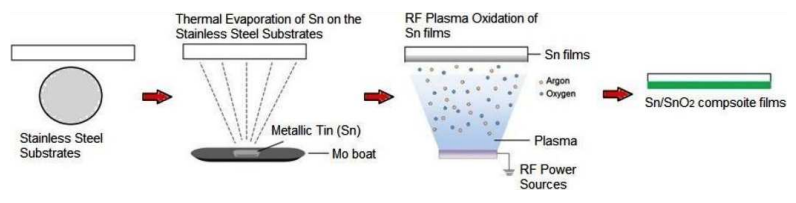

Fig. 1. Schematic representations of methods for preparing $\mathrm{Sn} / \mathrm{SnO}_{2}$ composite films.

An X-ray diffractometer (Rigaku D/MAX 2000), scanning electron microscopy SEM (JEOL 6060LV) and MTI BST8-MA Battery Analyzer were used for characterization of the composite films. Coin-type (CR2016) test cells were assembled in an argon-filled glove box, directly using the $\mathrm{Sn} / \mathrm{SnO}_{2}$ coated stainless steel substrates as the working electrode, a lithium metal foil as the counter electrode, a micro porous polypropylene (PP) membrane (Cellgard 2300) as the separator, and $1 \mathrm{M}$ solution of LiPF6 in ethylene carbonate (EC) and dimethyl carbonate (DMC) (1:1 by weight) as the electrolyte. The cells were charged and discharged between $0.1 \mathrm{~V}$ and $2.0 \mathrm{~V}$ at different current density. 


\section{Results and discussion}

The crystal structures of both the thermally evaporated and oxidized coating samples were determined using XRD with $\mathrm{Cu} K_{\alpha}$ radiation. Figure 2 shows a typical XRD pattern for the pure tin (Sn) films evaporated onto the stainless steel substrates in an argon atmosphere at a pressure of 1.0 Pa (JCPDS file no. 01-086-2264 for powder Sn) and a SEM image. No obvious reflection peaks from impurities were detected, providing evidence of the high purity of the product. After thermal evaporation onto a stainless steel substrate, tin exhibits a crystalline microstructure with epitaxial grains as shown in Fig. $2 b$. The grain sizes have been calculated with Scherrer's formula. The calculated grain size of the tin film that was thermally evaporated in a 1.0 Pa Ar atmosphere is $34 \mathrm{~nm}$.

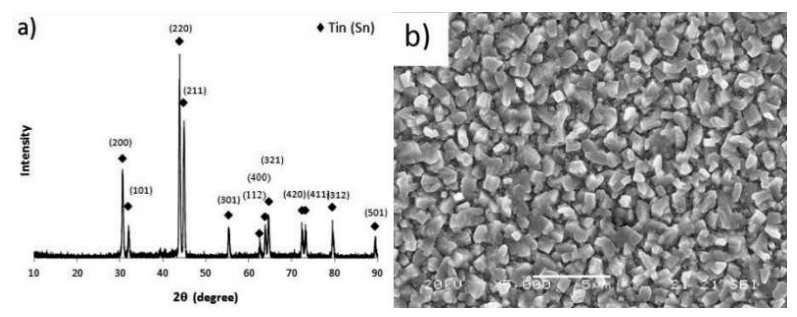

Fig. 2. (a) XRD pattern and (b) SEM image of pure tin (Sn) film evaporated at $1 \mathrm{~Pa}$ Ar.

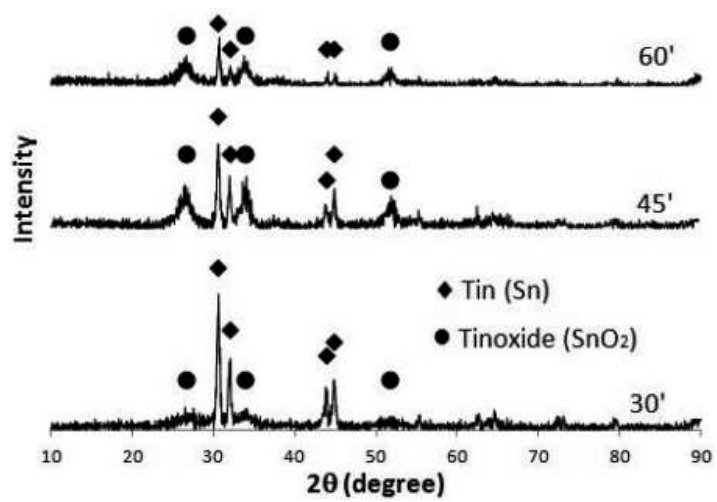

Fig. 3. XRD patterns of the tin and tin oxide $\left(\mathrm{Sn} / \mathrm{SnO}_{2}\right)$ films.

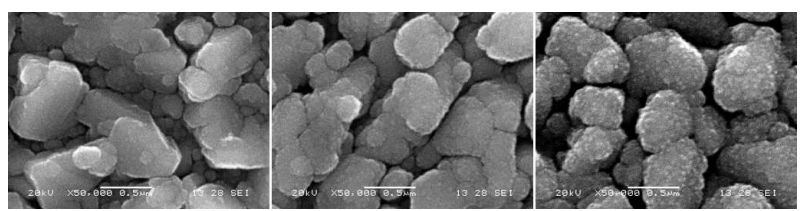

Fig. 4. SEM images of $\mathrm{Sn} / \mathrm{SnO}_{2}$ composite films produced by plasma oxidation for $30 \mathrm{~min}$ (a), $45 \mathrm{~min}$ (b) and $60 \mathrm{~min}$ (c) after thermal evaporation of Sn.

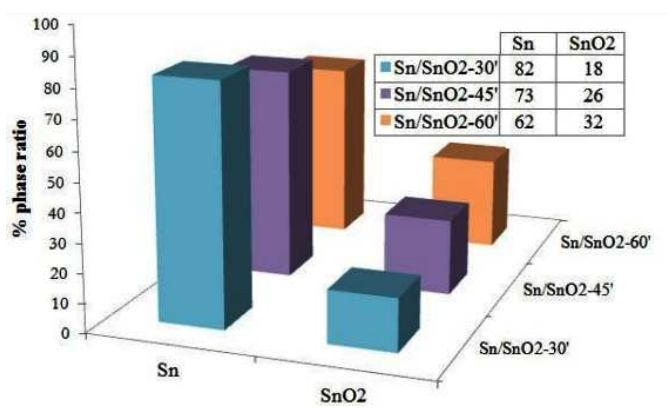

Fig. 5. \% phase ratio of $\mathrm{Sn} / \mathrm{SnO}_{2}$ composite films.

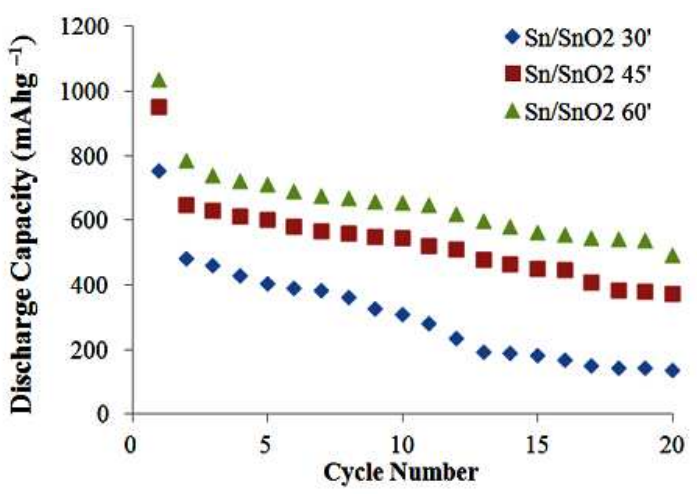

Fig. 6. Comparison of specific discharge capacities of $\mathrm{Sn} / \mathrm{SnO}_{2}$ composite films.

After the thermal evaporation process, the tin samples were subjected to a RF plasma oxidation process for three different oxidation times of 30,45 , and $60 \mathrm{~min}$ to produce $\mathrm{Sn} / \mathrm{SnO}_{2}$ nanocomposites films. The XRD patterns of the tin and tin oxide films produced for three different oxidation times of 30,45 , and $60 \mathrm{~min}$ are presented in Fig. 3. The films have a $\mathrm{Sn}$ and $\mathrm{SnO}_{2}$ structure, which agrees well with the standard data files (Sn:JCPDS No. 01-089-2958 and $\mathrm{SnO}_{2}$ : JPDS No. 01-077-0447), and all of the films have a crystalline structure. Increasing oxidation time resulted in increasing intensity of $\mathrm{SnO}_{2}$ peak while decreasing intensity of $\mathrm{Sn}$ peak.

The morphology of $\mathrm{Sn} / \mathrm{SnO}_{2}$ films produced at various plasma oxidation times from $30 \mathrm{~min}$ to $60 \mathrm{~min}$ were taken by SEM and displayed in Fig. 4 . The particle shape was maintained to relatively round with the increasing plasma oxidation time [3].

For all $\mathrm{Sn} / \mathrm{SnO}_{2}$ composite films, quantitative phase analysis was performed in order to determine the relative phase amounts using the Rietveld refinement method with helping Rigaku software, as shown in Fig. 5. Increasing oxidation time resulted in increasing tin oxide percent and decreasing tin percent.

The discharge capacity vs. the number of cycles for cells made from $\mathrm{Sn} / \mathrm{SnO}_{2}$ films is shown in Fig. 6. The results show that the discharge specific capacity of the $\mathrm{Sn} / \mathrm{SnO}_{2}$ films increases with increasing amount of $\mathrm{SnO}_{2}$ 
in the composite. Similar relationship between $\mathrm{SnO}_{2}$ ratio and specific capacity values has been obtained by Sivashanmugam et al. [4]. Furthermore, the composites with a higher rate of $\mathrm{SnO}_{2}$ exhibit a low capacity fade.

\section{Conclusions}

Crystalline pure tin ( $\mathrm{Sn}$ ) film with a grain size of $34 \mathrm{~nm}$ was thermally evaporated on the stainless steel substrates in $1 \mathrm{~Pa} \mathrm{Ar}$ atmosphere. The tin films were subjected to $\mathrm{RF}$ plasma oxidation in $\mathrm{Ar}+\mathrm{O}_{2}$ atmospheres for three different times $(30,45$, and $60 \mathrm{~min})$ and $\mathrm{Sn} / \mathrm{SnO}_{2}$ nanocomposite films have been successfully obtained. According to RF plasma oxidation time, the ratios of $\mathrm{Sn}: \mathrm{SnO}_{2}$ are 82:18, 73:26 and 62:32. $\mathrm{Sn} / \mathrm{SnO}_{2}$ nanocomposite films were used as an electrode for Li-ion cells and discharge capacity values increase with increasing amount of $\mathrm{SnO}_{2}$ in the composite.

\section{Acknowledgments}

The authors would like to acknowledge the financial support of Scientific and Technical Research Council of Turkey (TUBITAK) under the contract no. 109M464 and Sakarya University Commission for Scientific Research Projects under the contract no. 2010-50-02-017.

\section{References}

[1] C. de las Casas, W. Li, J. Power Sources 208, 74 (2012)

[2] S.T. Chang, I.C. Leu, M.H. Hon, J. Alloys Comp. 403, 335 (2005)

[3] Y. Kim, Y. Yoon, D. Shin, J. Anal. Appl. Pyrolysis 85, 557 (2009)

[4] A. Sivashanmugam, T. Prem Kumar, N.G. Renganathan, S. Gopukumar, M. Wohlfahrt-Mehrens, J. Garche, J. Power Sources 144, 197 (2005) 